\title{
PROBIOTIC BIOFILM ON CARRIER SURFACE: A NOVEL PROMISING APPLICATION FOR FOOD INDUSTRY
}

\author{
M. Grossova*, P. RysavKa and I. Marova \\ Faculty of Chemistry, Department of Food Chemistry and Biotechnology, Brno University of Technology, \\ Purkynova 118, CZ-61200 Brno. Czech Republic
}

(Received: 25 November 2016; accepted: 13 March 2017)

\begin{abstract}
In this essay work, the ability of probiotic biofilm formation on carrier surface was demonstrated. Probiotic biofilms exhibit the same properties as pathogen microbial biofilms but with higher resistance to low $\mathrm{pH}$ values and bile salts. The ability of different probiotic strains (Lactobacillus acidophilus, Bifidobacterium breve, Bifidobacterium longum) to interact with pre-selected carriers divided into 3 categories (polymers, complex food matrices, and inorganic compounds) was tested. Lactobacillus acidophilus and Bifidobacterium longum combined with inorganic silica carrier exhibited the interaction leading to biofilm formation only. Prepared biofilm (Lactobacillus acidophilus) was then subjected to comparative study with planktonic bacterial culture. The ability to survive in the presence of low $\mathrm{pH}$ value $(\mathrm{pH} 1-3)$ and bile salts $(0.3 \%$ solution) was evaluated. Low $\mathrm{pH}$ value $(\mathrm{pH} 1)$ had a harsh effect on free cell culture causing decreased cell viability $(71.9 \pm 3.2 \%$ of viable cells). Biofilm culture exhibited higher resistance to low $\mathrm{pH}$ value, the viability exceeded $90 \%$. The exposure of free cell probiotic culture to porcine bile resulted in an almost constant decrease in viability during the study period ( $68.2 \pm 1.1 \%$ of viable cells, after 240 min incubation). Viability of biofilm after the exposition to bile was almost constant with a slight decrease of no more than $5 \%$ during the study.
\end{abstract}

Keywords: probiotics, biofilm, carrier, acid tolerance, bile tolerance

The first mention of probiotics appeared at the beginning of the $20^{\text {th }}$ century in the writings of Elie Metchnikoff. He suggested that the longevity and healthy life of Bulgarian people is hidden in their consumption of fermented milk products (TripaThI \& GirI, 2014). In 2001, probiotics as "live microorganisms, which when administered in adequate amounts confer a health benefit on the host" (FAO/WHO, 2001) was defined.

During the last $15-20$ years, it was recognized that the developmental process of biofilm formation is the natural way of life for microorganisms, without differences between harmful and commensal microorganisms. Therefore, on one hand, biofilm formation is an important clinical pathogenic mechanism, a menace to the aging population, immunocompromised and poly-traumatic patients, on the other hand, a modern medical instrumental intervention (RömLING et al., 2014). In the common line, biofilm cells have a higher resistance to antimicrobial agents and agents harmful to microbes in biofilm than planktonic bacteria. The formation of a barrier or biofilm prohibits the direct contact with harmful agents (SREY et al., 2013).

\footnotetext{
* To whom correspondence should be addressed.

Phone: +420 736468 302; e-mail: grossova@favea.cz
}

This is an open-access article distributed under the terms of the Creative Commons Attribution 4.0 License, which permits unrestricted use, distribution, and reproduction in any medium for non-commercial purposes, provided the original author and source are credited. 
Probiotics, including Lactobacillus and Bifidobacterium species, have been found also to naturally exist in the gut in the complex biological conglomerate called biofilm, which tightly adheres to the gut lining (CAGGianielLo et al., 2016). Biofilm is a sessile high-density community of bacterial cells, which is shielded by a self-secreted protective layer formed by extracellular polymeric substance (EPS) (CHEOW \& HADINOTO, 2013). Although the exact mechanism of acting of EPS is still unknown, cells involved in biofilm exhibit a specific rate of resistance presumably (CAGGiANIELlo et al., 2016) due to (i) the specific dormant metabolic state of biofilm cells and their specific communication called quorum sensing and/or (ii) the protective function of the EPS (VENTOLINI, 2015). Moreover, the protection of bacterial cells against harsh biotic and abiotic conditions including temperature, $\mathrm{pH}$, and osmotic stress during passage through intestinal tract, EPS can also be involved in adhesion to surfaces and biofilm formation and in cell adhesion/recognition mechanisms (DonOT et al., 2012; SALAZAR et al., 2016).

The protective function of biofilm on cells starts considerations on the application of this knowledge in pharmaceutical and food industry, where probiotic cells are stressed by handling, storage, and digestion and, therefore, they lose their potential healthy activity.

The aims of the present study were to evaluate the abilities of probiotic strains to form biofilm on a wide range of carriers, and to compare biofilm formation on the selected surfaces. The viability of biofilm at low $\mathrm{pH}$ and in the presence of bile was evaluated under model conditions. Thus, harsh conditions of the gastrointestinal tract were induced to assess differences in the survival of planktonic and biofilm forms of probiotic bacteria.

\section{Materials and methods}

\subsection{Materials}

The following materials were used in the present work as carriers: poly-(vinyl-pyrrolidoneco-vinyl acetate), nano-cotton, potatoes fibre, sodium alginate, carrageenan, oat fibre, calcium phosphate, zinc oxide, silica, and finely milled complex food matrices (i.e. flour, groats of oats, pea, lentils, poppy, and buckwheat). Complex food matrices were bought from local markets and milled in the laboratory. Silica was provided by Pharmaceutical Biotechnology $(\mathrm{CZ})$. All other ingredients used in the cultivation step were of pharmaceutical quality and could be purchased as standard pharmaceutical ingredients for food supplements production or drug production.

\subsection{Microorganisms and cultivation media}

The adherence abilities of probiotic strains to selected carriers were evaluated for three different bacteria: Lactobacillus acidophilus (CCM 4833), Bifidobacterium longum (CCM 4990), and Bifidobacterium breve (CCM 3763). All tested bacteria in this study were provided by the Czech Collection of Microorganisms in Brno. Probiotic bacterial cultures were grown in commercial deMan, Rogosa and Sharpe (MRS) broth (Lactobacillus acidophilus) and Bifidobacterium broth with and without carriers. Both media were delivered by Himedia. The media were supplemented with $1.5 \% \mathrm{w} / \mathrm{v}$ carries. All strains were cultivated at $37{ }^{\circ} \mathrm{C}$ for $16-24 \mathrm{~h}$. 


\subsection{Determination of biofilm formation}

The creation of biofilm was performed by static fermentation. The biofilm formulation was assessed by Gram-staining and observed under optical microscope (Nikon Eclipse E 400). The biofilm formation was confirmed by electron microscope (Mira3 Tescan).

\subsection{Determination of viability in low $\mathrm{pH}$ environment}

A solution simulating the stomach environment with a composition of $\mathrm{NaCl}\left(2.05 \mathrm{~g} \mathrm{l}^{-1}\right)$, $\mathrm{KH}_{2} \mathrm{PO}_{4}\left(0.60 \mathrm{~g} \mathrm{l}^{-1}\right), \mathrm{CaCl}_{2}\left(0.11 \mathrm{~g} \mathrm{l}^{-1}\right)$, and $\mathrm{KCl}\left(0.37 \mathrm{~g} \mathrm{l}^{-1}\right)$ was prepared according to CORCORAN and co-workers (2005). The $\mathrm{pH}$ of the solution was adjusted to values 1,2 , and 3 by $1 \mathrm{M} \mathrm{HCl}$. Fresh biofilm culture after cultivation, where the high degree of adhesion was confirmed by electron microscope, and planktonic form culture were incubated in prepared acidic solutions in a shaker at $37^{\circ} \mathrm{C}$ for $120 \mathrm{~min}$. At 30,60 , and $120 \mathrm{~min}$, the samples were taken and neutralized by $1 \mathrm{M} \mathrm{NaHCO}_{3}$. The number of CFU in the prepared sample was determined according to a modified Miles-Misra method (Miles, 1979; Hedges, 2002).

Each experiment was performed in three replications. The viability of the biofilm and planktonic form was expressed as a percentage of viable cells at the sampling time to the viable cell at the start of the experiment.

\subsection{Determination of probiotic cells viability in bile}

The bile tolerance of Lactobacillus acidophilus CCM 4833 strain in planktonic and biofilm form was evaluated. Samples of probiotic cells' fresh cultures grown in the presence of silica carrier and without carrier were incubated in the $0.3 \%$ solution of bile salts (Sigma) for $4 \mathrm{~h}$ at $37^{\circ} \mathrm{C}$ (Ruas-Madiedo \& De Los Reyes-Gavilan, 2005). In the period of 1 hour the samples were taken and the CFU number was determined according to Miles-Misra methods (MiLEs, 1979; HedGES, 2002). Each experiment was performed in three replications.

\subsection{Statistical analysis}

Two-sample Student's unpaired $t$-test for the evaluation has been used. This test can determine whether the two normal distributions with the same variance, coming from two independent samples, have the same mean. The conformity of variances has been verified by $F$-test. If the resulting P-value $>0.05$, the variances of both data can be treated as equal, $t$-test can be used.

\section{Results and discussion}

\subsection{Probiotic biofilm formation on carrier surface}

Materials investigated in this work were chosen according to the following criteria: (i) carrier has to be commonly used in the pharmaceutical industry, (ii) according to the legislation, carrier has to be used in food supplements, and (iii) carrier has to be insoluble in boiling water. The screening of the selected materials studied for biofilm formation for three different probiotic strains is given in Table 1. Surprisingly, the best biofilm formation was observed in the case of Lactobacillus acidophilus and Bifidobacterium longum on silica. On the other hand, silica was not an appropriate carrier for Bifidobacterium breve. Figure 1 shows the rate of adhesion of Lactobacillus acidophilus and Bifidobacterium longum on the silica carrier. 

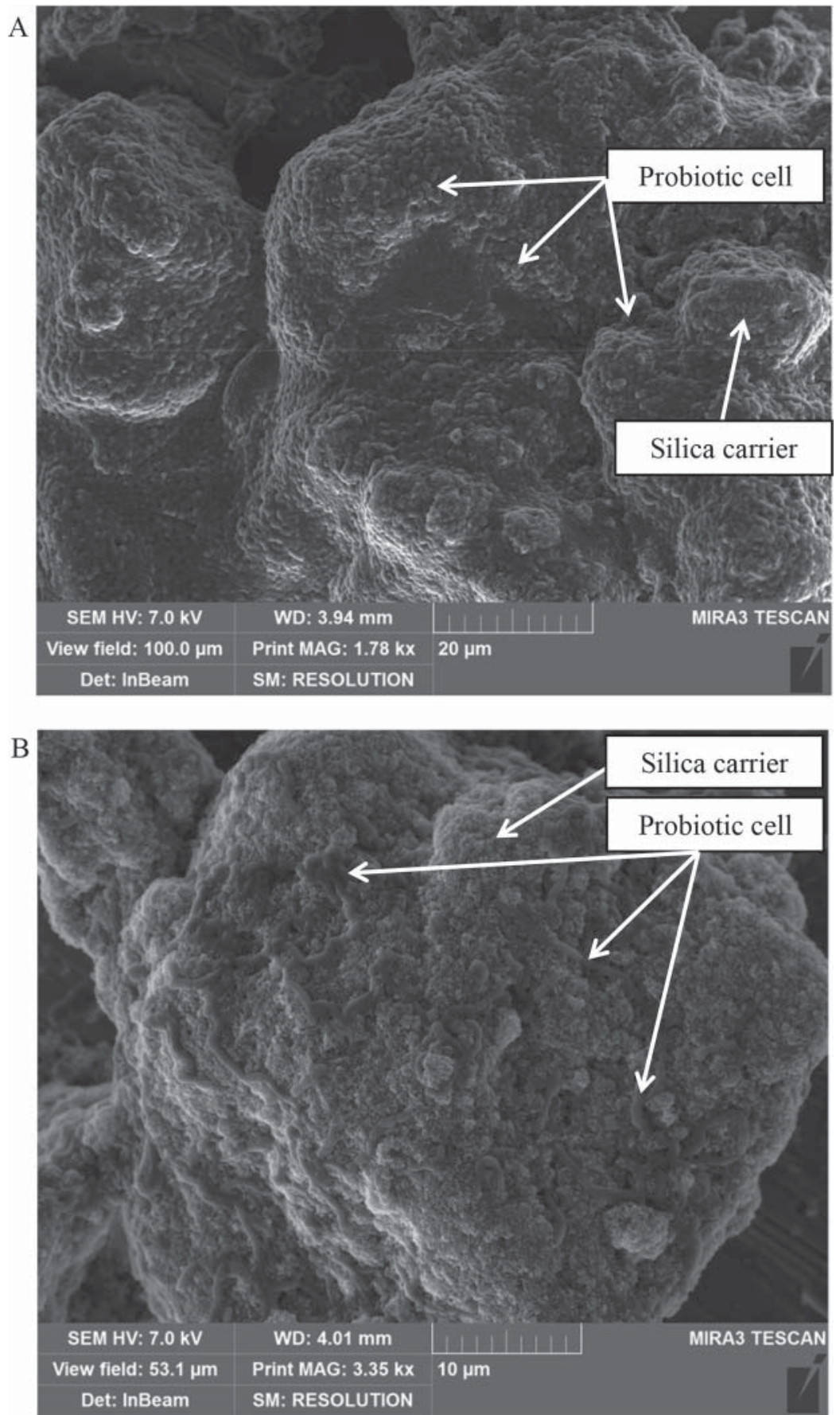

Fig. 1. Probiotic biofilm on silica carrier (A): Lactobacillus acidophilus; (B): Bifidobacterium longum; under electron microscope Mira3 Tescan 
Sodium alginate, potatoes fibre, carrageenan, oat fibre, pea, and buckwheat showed partial adhesion of Lactobacillus strain only, which was later on rejected. Thanks to a complex and polymeric structure of studied materials, it was later found that probiotic cells are detained in the complex structure of carriers and biofilm formation was not confirmed. Sodium alginate, potatoes fibre, oat fibre, and buckwheat show the same properties in the presence of Bifidobacterium longum; and sodium alginate, oat fibre, pea, and buckwheat in the presence of Bifidobacterium breve. Nano-cotton, poly(vinylpyrrolidone-co-vinyl acetate), corn starch, calcium phosphate, kaolin, flour, groats of oats, lentils, and poppy were not suitable materials for adhesion of Lactobacillus and Bifidobacterium strains. In Figure 2 biofilm formation in the presence of silica observed by optical microscopy is introduced. Furthermore, Bifidobacterium longum did not exhibit the ability to form biofilm on the surface of carrageenan and finely milled pea, and Bifidobacterium breve did not form biofilm in the presence of potatoes fibre and carrageenan.

Table 1. Formation of probiotic biofilm (Lactobacillus acidophilus, Bifidobacterium longum, and Bifidobacterium breve) on selected carriers

\begin{tabular}{|c|c|c|c|}
\hline Selected carrier & $\begin{array}{c}\text { Lactobacillus } \\
\text { acidophilus } \\
\text { (CCM 4833) }\end{array}$ & $\begin{array}{c}\text { Bifidobacterium } \\
\text { longum } \\
\text { (CCM 4990) }\end{array}$ & $\begin{array}{c}\text { Bifidobacterium } \\
\text { breve } \\
\text { (CCM 3763) }\end{array}$ \\
\hline \multicolumn{4}{|l|}{ Polymers } \\
\hline Poly (vinylpyrrolidone-co-vinyl acetate) & - & - & - \\
\hline Sodium alginate & + & + & + \\
\hline Nanocotton & - & - & - \\
\hline Potato fibre & + & + & - \\
\hline Carrageenan & + & - & - \\
\hline Oat fibre & + & + & + \\
\hline Corn starch & - & - & - \\
\hline \multicolumn{4}{|l|}{ Mineral compounds } \\
\hline Calcium phosphate & - & - & - \\
\hline Kaolin & - & - & - \\
\hline Silica & ++ & ++ & - \\
\hline \multicolumn{4}{|l|}{ Complex food matrices } \\
\hline Flour (finely milled) & - & - & - \\
\hline Groat of oats (finely milled) & - & - & - \\
\hline Pea (finely milled) & + & - & + \\
\hline Lentils (finely milled) & - & - & - \\
\hline Poppy (finely milled) & - & - & - \\
\hline Buckwheat (finely milled) & + & + & + \\
\hline
\end{tabular}

Data are evaluated as a rate of adhesion to the carrier, where -: no adhesion, $+:$ probiotic cells are detained into the complex structure of carriers; ++ : adhesion of probiotic cells on the carrier.

The data presented in Table 1 show that probiotic strains are able to adhere to some carrier surface and form biofilm. Furthermore, the present results suggest that the adherence is driven by properties of both selected carrier and probiotic strain. 


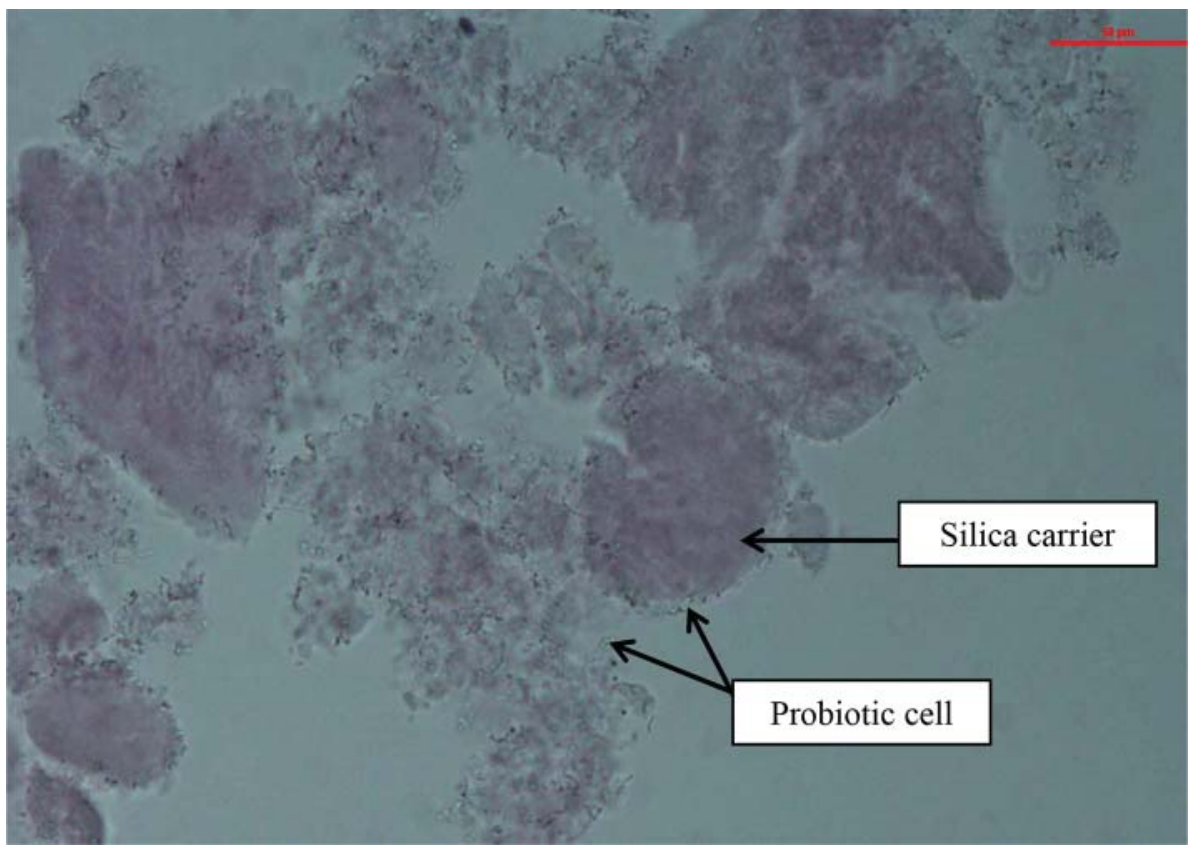

Fig. 2. Lactobacillus acidophilus CCM 4833 in the presence of silica under optical microscope NIKON Eclipse E 400 (figure size: $50 \mathrm{~mm}$ )

The properties of surfaces, carrier top layer and probiotic cell, are responsible for adhesion, and thus, this ability is ensured by the sum of specific (mediated by different pililike structures managed by genetic assembly system (LoNGO et al., 2014)) and nonspecific (driven by electrostatic and hydrophobic forces, steric hindrance, van der Waals forces, temperature, $\mathrm{pH}$, and hydrodynamic forces (DunNe, 2002)) interactions between these two surfaces. Although biofilm formation on different carriers is well known in the case of pathogenic or commensal microorganisms, probiotic strains have not yet been subjected to study for biofilm formation, especially on free carriers. There are some studies focusing on biofilm formation on polystyrene microplates (AoudiA et al., 2016), but silica and other here presented materials have not been tested yet.

The tests performed have not confirmed adherence of probiotic strain to more than one carrier. Elementary/single carrier particles are proposed as the preferable material suitable for adhesion of probiotic strains. On the other hand, food matrices contain a wide range of components and they may not offer a coherent surface for probiotic adhesion.

The properties of cell surface are connected to the type of microorganism. This study confirmed that the ability of adhesion and subsequent biofilm formation on the carrier is dependent on the type of microorganism. Similarities among studied strains and carrier suitable for all studied probiotic strains were not found. Therefore, we expect that strain dependent properties play unmistakable roles also in biofilm formation. This concept was proposed also by other authors who studied biofilm formation on polystyrene microplate (Aoudia et al., 2016). 


\subsection{The viability of probiotic cells at low $\mathrm{pH}$}

To apply their effect in the intestine and to confer any health benefits to the host, probiotic bacteria should be capable of surviving the passage through the gastrointestinal tract, which presents low $\mathrm{pH}$ in the stomach and bile in the small intestine tract (TulumogLu et al., 2013). Therefore, high acid level tolerance was evaluated as a critical parameter of a good source of probiotics in the pharmaceutical industry.

In the present study, the viability of probiotic cells in biofilm and in planktonic state subjected to low $\mathrm{pH}$ values was studied. The viability of cells was expressed as CFU units and calculated also as a percentage of viable cells in the sample to viable cells in the control culture, which was prepared under standard cultivation conditions of Lactobacillus acidophilus CCM4833 (Table 2). Biofilm bacterial cells, as it could be expected, are more resistant than planktonic cells at low $\mathrm{pH}(\mathrm{pH} 1)$ at all times studied. The drop of viability was observed during the whole experiment, and the highest rate of decrease was observed after $120 \mathrm{~min}$. While planktonic culture showed just $71.9 \pm 3.2 \%$, biofilm sample exhibited $90.5 \pm 0.1 \%$ of viability.

\begin{tabular}{cccccc}
\multicolumn{5}{c}{ Table 2. Average change in number of surviving bacteria under low pH } \\
\hline pH & $\begin{array}{c}\text { Incuba- } \\
\text { tion time } \\
(\text { min) }\end{array}$ & $\begin{array}{c}\text { CFU value without } \\
\text { carrier } \\
\text { (expressed as percent- } \\
\text { age of control \%) }\end{array}$ & $\begin{array}{c}\text { CFU value without } \\
\text { carrier } \\
\text { (cell number) }\end{array}$ & $\begin{array}{c}\text { CFU value with } \\
\text { carrier (expressed as } \\
\text { percentage of control } \\
\text { \%) }\end{array}$ & $\begin{array}{c}\text { CFU value with } \\
\text { carrier } \\
\text { (cell number) }\end{array}$ \\
\hline Control & 0 & $100.0 \pm 0.1$ & $7.30 \cdot 10^{8} \pm 7 \cdot 10^{5}$ & $100.0 \pm 0.1$ & $5.40 \cdot 10^{8} \pm 5 \cdot 10^{5}$ \\
& 30 & $(75.5 \pm 1.8)^{\mathrm{a}}$ & $5.51 \cdot 10^{8} \pm 1 \cdot 10^{7}$ & $(95.7 \pm 0.4)^{\mathrm{a}}$ & $5.17 \cdot 10^{8} \pm 2 \cdot 10^{6}$ \\
1 & 60 & $(71.9 \pm 3.2)^{\mathrm{b}}$ & $5.25 \cdot 10^{8} \pm 1 \cdot 10^{7}$ & $(93.2 \pm 0.2)^{\mathrm{b}}$ & $5.03 \cdot 10^{8} \pm 1 \cdot 10^{6}$ \\
& 120 & $(71.9 \pm 3.2)^{\mathrm{c}}$ & $5.25 \cdot 10^{8} \pm 1 \cdot 10^{7}$ & $(90.5 \pm 0.1)^{\mathrm{c}}$ & $4.89 \cdot 10^{8} \pm 5 \cdot 10^{5}$ \\
& 30 & $(85.5 \pm 3.2)^{\mathrm{d}}$ & $6.24 \cdot 10^{8} \pm 2 \cdot 10^{7}$ & $(95.6 \pm 2.6)^{\mathrm{d}}$ & $5.16 \cdot 10^{8} \pm 1 \cdot 10^{7}$ \\
& 60 & $(86.5 \pm 1.5)^{\mathrm{e}}$ & $6.31 \cdot 10^{8} \pm 1 \cdot 10^{7}$ & $(91.8 \pm 0.3)^{\mathrm{e}}$ & $4.96 \cdot 10^{8} \pm 2 \cdot 10^{6}$ \\
& 120 & $(75.5 \pm 2.3)^{\mathrm{f}}$ & $5.51 \cdot 10^{8} \pm 2 \cdot 10^{7}$ & $(90.7 \pm 0.4)^{\mathrm{f}}$ & $4.90 \cdot 10^{8} \pm 2 \cdot 10^{6}$ \\
& 30 & $(84.7 \pm 2.3)^{\mathrm{g}}$ & $6.18 \cdot 10^{8} \pm 2 \cdot 10^{7}$ & $(94.8 \pm 0.3)^{\mathrm{g}}$ & $5.12 \cdot 10^{8} \pm 2 \cdot 10^{6}$ \\
& 60 & $(88.4 \pm 1.3)^{\mathrm{h}}$ & $6.45 \cdot 10^{8} \pm 9 \cdot 10^{6}$ & $(94.8 \pm 0.4)^{\mathrm{h}}$ & $5.12 \cdot 10^{8} \pm 2 \cdot 10^{6}$ \\
& 120 & $(75.5 \pm 1.8)^{\mathrm{i}}$ & $5.51 \cdot 10^{8} \pm 1 \cdot 10^{7}$ & $(93.8 \pm 0.7)^{\mathrm{i}}$ & $5.07 \cdot 10^{8} \pm 4 \cdot 10^{6}$ \\
\hline
\end{tabular}

Data are evaluated as average value and standard deviation. Mean values are the average of at least three replicates \pm standard deviation. Values with the same letters in the each line were evaluated $(\mathrm{P}>0.05)$. Statistical difference was not confirmed between values marked by letter $\mathrm{d}$ and $\mathrm{h}$. Values with letters $\mathrm{d}$ and $\mathrm{h}$ in the same line are not statistically different $(\mathrm{P}>0.05)$.

Furthermore, a higher $\mathrm{pH}$ value ( $\mathrm{pH}$ 2) indicates a partially suitable environment for probiotic viability. After $30 \mathrm{~min}$, the free cell culture exhibited some kind of adaptation. At other monitored time points differences between viabilities were found. The greatest difference was measured after $120 \mathrm{~min}$ of incubation, where biofilm culture exhibited $90.7 \pm 0.4 \%$ and free cells sample achieved $75.5 \pm 2.3 \%$ of viable cells.

At the last tested $\mathrm{pH}$ value $(\mathrm{pH} 3)$ bacteria also showed a partial adaptation to the environment. Especially, after $60 \mathrm{~min}$ incubation, increased resistance to low $\mathrm{pH}$ of free cells was observed. A sample without carrier exhibited $88.4 \pm 1.3 \%$ of viability and biofilm sample achieved $94.8 \pm 0.4 \%$ of cell viability. 
The hypothesis that bacterial cells in biofilm on the carrier are more stable at low $\mathrm{pH}$ was confirmed. The difference between viability of biofilm and free cells exceeded $15 \%$ at all studied $\mathrm{pH}$ values after 120 min cultivation. Furthermore, the viabilities of free cells oscillated around $72 \%$ and viabilities of biofilm cultures exceeded $90 \%$.

Although most sources indicate a high decrease in the viability of free cells upon contact with the environment of the stomach compared to encapsulated or immobilized probiotics (GEBARA et al., 2013; FIJAŁKOWSKI et al., 2016), there is still a lack of comprehensive data in the case of biofilm formed on free carrier. Some kinds of probiotic biofilm forms were studied, but these works focused on resistance to stresses of self-forming biofilm encapsulated in natural polymers. Such biofilms exhibited a higher resistance to processing and digestion stresses than encapsulated planktonic cells (CHEOW et al., 2014), but the resistance of biofilm on free carriers was not documented yet.

The obtained results are in agreement with the published data of DOLEYRES and LACROIX (2005). According to these authors, the immobilized population of bifidobacteria with sufficient high cell density could induce a quorum-sensing response, leading to the improvement in physical and technological characteristics of lactic acid bacteria, especially adaptation to changing environmental conditions (Doleyres \& LACroix, 2005). On the other hand, the viability of both free cell culture and biofilm is strictly dependent on the $\mathrm{pH}$ value, but linear dependence of decrease in cell viability as the function of $\mathrm{pH}$ was not confirmed. Furthermore, the results show that free cell cultures can also exhibit a weak resistance to low $\mathrm{pH}$ value.

\subsection{The viability of probiotic cells in the presence of bile salts}

The comparison of resistance of planktonic form and biofilm form cultures is given in Table 3. The viability of planktonic culture was greatly influenced by bile salts, and at study points $(60,120,180$, and $240 \mathrm{~min})$ viability decreased to $78.9 \pm 1.8 \%, 77.3 \pm 0.7 \%, 74.2 \pm 1.4 \%$, and $68.2 \pm 1.1 \%$, respectively. While the percentage of viable cells of planktonic culture dropped to $68.2 \pm 1.1 \%$, the percentage viability of the biofilm cells remained $98.2 \pm 1.0 \%$ even after $4-h$ treatment. Whereas free cell culture exhibited a decreasing linear trend, biofilm culture subjected to $0.3 \%$ bile salts solution showed an almost constant value during the whole studied period. Lactobacillus acidophilus CCM 4833 biofilm on the appropriate carrier was more resistant to bile than free cell culture at all studied time points.

Table 3. Percentage of surviving bacteria in $0.3 \%$ bile salts

\begin{tabular}{ccccc}
\hline $\begin{array}{l}\text { Time } \\
\text { (hour) }\end{array}$ & $\begin{array}{c}\text { Average of change in } \\
\text { CFU without carrier (\%) }\end{array}$ & $\begin{array}{c}\text { CFU value without } \\
\text { carrier } \\
\text { (cell number) }\end{array}$ & $\begin{array}{c}\text { Average of change in } \\
\text { CFU with carrier (\%) }\end{array}$ & $\begin{array}{c}\text { CFU value without } \\
\text { carrier } \\
\text { (cell number) }\end{array}$ \\
\hline 0 & $100.0 \pm 1.6$ & $6.80 \cdot 10^{8} \pm 1 \cdot 10^{7}$ & $100.0 \pm 0.7$ & $4.50 \cdot 10^{8} \pm 3 \cdot 10^{6}$ \\
60 & $78.9 \pm 1.8$ & $5.37 \cdot 10^{8} \pm 1 \cdot 10^{7}$ & $97.5 \pm 1.0$ & $4.39 \cdot 10^{8} \pm 5 \cdot 10^{6}$ \\
120 & $77.3 \pm 0.7$ & $5.26 \cdot 10^{8} \pm 5 \cdot 10^{6}$ & $95.6 \pm 1.9$ & $4.30 \cdot 10^{8} \pm 9 \cdot 10^{6}$ \\
180 & $74.2 \pm 1.4$ & $5.05 \cdot 10^{8} \pm 1 \cdot 10^{7}$ & $97.0 \pm 1.2$ & $4.37 \cdot 10^{8} \pm 5 \cdot 10^{6}$ \\
240 & $68.2 \pm 1.1$ & $4.64 \cdot 10^{8} \pm 7 \cdot 10^{6}$ & $98.2 \pm 1.0$ & $4.42 \cdot 10^{8} \pm 5 \cdot 10^{6}$ \\
\hline
\end{tabular}

Data are evaluated as average value and standard deviation. Mean values are the average of at least three replicates \pm standard deviation. All values in the same line are statistically different $(\mathrm{P}>0.05)$. 
The previously presented results indicate that probiotic cells form biofilm as pathogenic or commensal organisms. Furthermore, probiotic biofilms gain also other features, such as bile tolerance, studied here. Although bile tolerance of probiotic biofilm on free carrier was not previously studied, bile tolerance of probiotic cells incorporated in biofilm on the free carrier can be expected.

Bile tolerance of probiotic cells greatly varies from strain to strain (RuIz et al., 2013) and may be dependent on the type of source from which the potential organism has been isolated. It has been reported that probiotic strains of human origin have a higher resistance to bile than of different origins (PANICKER \& BeHRE, 2014). Furthermore, some environmental factors, such as $\mathrm{pH}$ and temperature, may increase bile tolerance or enhance the survival rate of probiotic cells (LI, 2012).

\section{Conclusions}

In this study the biofilm formation of probiotic microorganisms on the surface of different carriers was tested. The prepared biofilm (Lactobacillus acidophilus CCM 4833) was subjected to low $\mathrm{pH}(\mathrm{pH} 1,2$, and 3$)$ and $0.3 \%$ solution of porcine bile salts. From the wide range of materials, insoluble in hot water and authorized for food supplements in the European Union, only silica was found as possible carrier for biofilm formation. The biofilm formation on a carrier provides protection to probiotics against low $\mathrm{pH}$ for a certain exposure time. Although the planktonic form of studied strain exhibited a weak adaptation at some points, the formation of biofilm showed better survival of probiotic cells. Bile tolerance of biofilm was also confirmed in comparison to free cell culture.

Silica as a carrier of probiotic cultures represents a new direction to increase stability and ensure higher efficiency of probiotics administered in food supplements or in food products.

The work was supported by the project „Materials Research Centre - Sustainability and Development” Nr. LO1211 of the Ministry of Education, Youth and Sports of the Czech Republic.

\section{References}

Aoudia, N., Rieu, A., Briandet, R., Deschamps, J., Chluba, J., Jego, G. \& Guzzo, J. (2016): Biofilms of Lactobacillus plantarum and Lactobacillus fermentum: Effect on stress responses, antagonistic effects on pathogen growth and immunomodulatory properties. Food Microbiol., 53, 51-59.

Caggianiello, G., Kleerebezem, M. \& Spano, G. (2016): Exopolysaccharides produced by lactic acid bacteria: from health-promoting benefits to stress tolerance mechanisms. Appl. Microbiol. Biot., 100, 3877-3888.

Cheow, W.S. \& Hadinoto, K. (2013): Biofilm-like Lactobacillus rhamnosus probiotics encapsulated in alginate and carrageenan microcapsules exhibiting enhanced thermotolerance and freeze-drying resistance. Biomacromolecules, 14, 3214-3222.

Cheow, W.S., Kiew, T.Y. \& Hadinoto, K. (2014): Controlled release of Lactobacillus rhamnosus biofilm probiotics from alginate-locust bean gum microcapsules. Carbohyd. polym., 103, 587-595.

Corcoran, B.M., Stanton, C., Fitzgerald, G.F. \& Ross, R.P. (2005): Survival of probiotic lactobacilli in acidic environments is enhanced in the presence of metabolizable sugars. Appl. Environ. Microb., 71, 3060-3067.

Doleyres, Y. \& Lacroix, C. (2005): Technologies with free and immobilised cells for probiotic bifidobacteria production and protection. Int. Dairy J., 15, 973-988. 
Donot, F., Fontana, A., Baccou, J.C. \& Schorr-Galindo, S. (2012): Microbial exopolysaccharides: Main examples of synthesis, excretion, genetics and extraction. Carbohyd. Polym., 87, 951-962.

Dunne, W.M. (2002): Bacterial adhesion: Seen any good biofilms lately? Clin. Microbiol. Rev., 15, $155-166$.

Fijalkowski, K., Peitler, D., Rakoczy, R. \& Żywicka, A. (2016): Survival of probiotic lactic acid bacteria immobilized in different forms of bacterial cellulose in simulated gastric juices and bile salt solution. LWTFood Sci. Technol., 68, 322-328.

FAO/WHO (2001): Report of a Joint FAO/WHO Expert Consultation on evaluation of health and nutrition properties of probiotics in food including powder milk with live lactic acid bacteria. Cordoba, Argentina. 30 pages.

Gebara, C., Chaves, K.S., Ribeiro, M.C.E., Souza, F.N., Grosso, C.R. \& Gigante, M.L. (2013): Viability of Lactobacillus acidophilus La5 in pectin-whey protein microparticles during exposure to simulated gastrointestinal conditions. Food Res. Int., 51, 872-878.

Hedges, A.J. (2002): Estimating the precision of serial dilutions and viable bacterial counts. Int. J. Food Microbiol., $76,207-214$.

LI, G. (2012): Intestinal probiotics: Interactions with bile salts and reduction of cholesterol. Procedia Environ. Sci., $12,1180-1186$.

Longo, F., Vuotto, C. \& Donelli, G. (2014): Biofilm formation in Acinetobacter baumannii. New Microbiol, 37, $119-127$

Miles, A.A. (1979): Citation classic - estimation of the bactericidal power of the blood. CC/Life Sci., L12-L12.

PANICKER, A.S. \& Behre, P.V. (2014): Evaluation of bile tolerance in dairy and human origin Lactobacillus fermentum strains. Indian J. Dairy Sci., 67, 421-425.

Römling, U., KJelleberg, S., Normark, S., Nyman, L., Uhlin, B.E. \& Åkerlund, B. (2014): Microbial biofilm formation: A need to act. J. Intern. Med., 276, 98-110.

Ruas-Madiedo, P. \& De Los Reyes-Gavilan, C.G. (2005): Invited review: Methods for the screening, isolation, and characterization of exopolysaccharides produced by lactic acid bacteria. J. Dairy Sci., 88, 843-856.

Ruiz, L., Margolles, A. \& Sanchez, B. (2013): Bile resistance mechanisms in Lactobacillus and Bifidobacterium. Front. Microbiol., 4, 396

Salazar, N., Gueimonde, M., Reyes-Gavilán, C.G. \& Ruas-Madiedo, P. (2016): Exopolysaccharides produced by lactic acid bacteria and bifidobacteria as fermentable substrates by the internal microbiota. Food Sci. Nutr., 56, $1440-1453$.

SREY, S., JAHID, I.K. \& HA, S.D. (2013): Biofilm formation in food industries: A food safety concern. Food Control, $31,572-585$

Tripathi, M.K. \& GIRI, S.K. (2014): Probiotic functional foods: Survival of probiotics during processing and storage. J. Funct. Foods, 9, 225-241.

Tulumoglu, S., Yuksekdag, Z.N., Beyatli, Y., Simsek, O., Cinar, B. \& Yașar, E. (2013): Probiotic properties of lactobacilli species isolated from children's faeces. Anaerobe, 24, 36-42.

Ventolini, G. (2015): Vaginal Lactobacillus: biofilm formation in vivo - clinical implications. Int. J. Womens Health, 7, 243-247. 